\title{
O LUGAR FLUTUANTE
}

\section{Sérgio Afonso Gonçalves Alves*}

Resumo: Este trabalho visa à discussão da literatura na Amazônia a partir de questões relacionadas a lugar, fronteira e espaço, noções estas que permeiam os escritos da região e nos levam a uma reflexão do espaço amazônico entremeado por elementos forâneos. Os termos aqui listados nos auxiliarão a compreender melhor o conceito de identidade cultural na Amazônia e a produção literária regional contemporânea. Entendemos que é fundamental o estudo da produção literária local por considerála ainda indicativa do contexto histórico, social e político dessa parte do Brasil, pois nos ajudará a construir uma ideia do local, regional e nacional, uma vez que o relato constrói a história imediata e social, relacionada ao lugar, fortemente marcado enquanto lugar de cultura. Portanto, compreender a Amazônia como o lugar de cultura é compreender o homem amazônico em seu contexto.

Palavras-chave: Amazônia; espaço; literatura.

Abstract: This paper aims to discuss literature in the Amazon from issues related to place, border and space, notions that permeate the writings of the region and lead us to a reflection about the Amazon region permeated by outsider elements. The terms listed here will help us to understand better the concept of cultural identity in the Amazon and contemporary regional literary production. We believe that it is important to study the local literary production because we consider it indicative of the historical, social and political development of this part of Brazil,

* Universidade Federal do Pará. 
since it will help us to build an idea of local, regional and national, because the report builds the immediate and social history, related to the place of culture, strongly marked as a place of culture. Therefore, understanding the Amazon as a place of culture is to understand the man in the Amazon in his context.

Keywords: Amazon; space; literature.

A literatura praticada na Amazônia, hoje, é uma literatura que repensa o espaço enquanto dimensão da realidade social, colocando-a como discurso que se insere no pensamento social. Literariamente, o espaço é pensado enquanto resultado das relações estabelecidas pela sociedade que se revela como expressão da particularidade de uma dada formação socioespacial, possibilitando reconhecer a região como ideia de diferenciação do espaço a partir de uma escala que a coloca entre o singular e o universal.

O reconhecimento que a literatura realiza do espaço faz com que ela identifique certas regularidades sociais que diferenciam esse espaço de outras áreas em um contexto sociocultural. Particularmente, porém, essa literatura admite que circulam nesse espaço signos de fora, abalando a ideia de fronteira geográfica, entendida de seu ponto de vista jurídico-administrativa. Nesses termos, a literatura revela processos de circulação que comunicam lugares distintos, a exemplo de fluxos de pessoas e de mercadorias, e anunciam, ao mesmo tempo, questões que perpassam por categorias como unidade, identidade e diferenciação. A paisagem, entendida como exteriorização das relações, nem sempre revela os conteúdos que dão conta do entendimento do espaço como totalidade. A literatura revela formações socioeconômicas e culturais que se imiscuem entre os muitos segmentos compondo o espaço social amazônico, por meio das representações de marcas culturais não só diferentes e desiguais, mas também contíguas, tais como as que acontecem nas áreas fronteiriças, onde a paisagem dá conta de mostrar a dinâmica que ali ocorre. 
Em função do posicionamento que escritores e poetas da Amazônia assumem diante de questões atuais, eles se apresentam como escritores-críticos que, olhando a região de um novo ângulo, apontam para algo diverso daquele pelo qual se via a região em épocas passadas como lugar do exótico, do estranho, do fantástico. Entretanto, a literatura contemporânea ainda não se libertou totalmente dos pejamentos do passado e a maioria dos autores se mantém orgulhosa da herança cultural-antropológico como legado a ser representado, sem negar que esse legado se encontra misturado a elementos outros, vindos de outros lugares, e que se integraram à vida amazônica. Uma das principais características desses autores refere-se à preocupação com as questões sociais e políticas, com questionamentos acerca dos grandes problemas urbanos, como a pobreza, a violência, o analfabetismo, a devastação da floresta, a degradação do meio ambiente, o que os torna homens do seu tempo, com um claro posicionamento crítico em relação às questões culturais específicas do seu lugar. Entendase aqui a noção de lugar como espaço caracterizado por relações imediatas pela proximidade social, trazendo em si o sentido do vivido, das imediações das relações cotidianas e das experiências dessas relações mediadas pelo espaço (TRINDADE JÚNIOR, 2010, p. 116). Há frequentemente a manutenção do particular, do pequeno e do diferente convivendo com o universal, o grandioso ou o que há de constante. Portanto, para essa literatura convergem dois pontos opostos: o novo, do mundo contemporâneo, que caminha por um processo de heterogeneização, e o homogêneo do mundo particularizado. Nessa dinâmica em que surge a circulação de signos diversos no mesmo espaço, a literatura costura pontos fixos - o que é característico do lugar - a pontos fluxos (SANTOS, 2009, p. 274 e s.), articulando uma rede de relações que nos ajuda a compreender a nova organização espacial.

Diante dessa reflexão, podemos afirmar que o momento atual é, sem dúvida, um momento fértil de criação literária, um marco diferenciado, aproximando-se daquele exercido na 
militância literária da geração das décadas de 50 e 60 do século XX (formada por Haroldo Maranhão, Max Martins, Benedito Nunes, Fernando Alonso, Rui Barata, Dalcídio Jurandir) e de um outro momento igualmente criativo na literatura da Amazônia do século XIX, representada por autores como Inglês de Souza e José Veríssimo. A obra da nova geração de autores que se enquadram no papel de críticos no contexto das transformações por que passa a região aponta para novos questionamentos ou para questionamentos tradicionais do espaço, porém com olhar diferente do usual, indicadores dos novos caminhos da literatura da região.

Por seu vasto território, seu manancial biológico e seu potencial para atividades agropecuárias, o destino da Amazônia parece ser o de abrigar os excedentes da população do CentroSul, os refugiados ecológicos de outras áreas brasileiras já atingidas pela devastação ambiental e como frente pioneira agrícola, mineral, e industrial, receptora de investimentos nacionais e estrangeiros (BENCHIMOL, 2009, p. 507). Diante desse quadro torna-se necessária uma política adequada e esclarecedora à sociedade dos perigos a que ela se expõe, da prática criminosa que fatalmente levará a região ao mesmo fim observado em outras áreas devastadas do planeta. Como se dá, neste momento, uma constante interação com outras culturas, percebe-se uma mobilidade identitária e cultural na região como nunca antes ocorrera na história, refletida na arte, provocando um rearranjo nas suas manifestações. É crescente a pressão que populações do Nordeste, do Centro-Sul e do Centro-Oeste exercem sobre os valores da região, com repercussões em vários setores da vida amazônica em muitas áreas da região, especificamente no sul dos estados. Particularmente, são inegáveis as consequências desse forte acometimento, cujas ressonâncias ricocheteiam nos desequilíbrios que atingirão sem dúvida o ecossistema e o modo de vida das populações nativas (BENCHIMOL, 2009, p 499). Essa questão já se mostra devidamente problematizada pela literatura local em obras que remontam o século XIX, com Inglês de Sousa, 
e chegam aos dias de hoje. Neste contexto, chegou-se à compreensão do quadro literário regional: decorre na região uma fase de mobilidade como causa dos novos arranjos sociais no contexto mundial, fazendo com que muitos poetas e escritores, conscientes dos problemas da região, como Thiago de Mello, cheguem a denunciar esse quadro crítico, exercendo uma função social e literária de voz do homem amazônico sem voz:

Índio aculturado é índio degradado (...) a maioria esmagadora dos nossos índios enfrenta hoje, perplexa perante si mesma, essa degradação imposta pelo branco e que começa já com o simples contato com o civilizado e que se prolonga sem nunca terminar, porque só acaba com a morte... (MELLO, 2005, p. 73)

O escritor Márcio Souza publicou um livro intitulado $O$ fim do terceiro mundo em que traduz com visões pessoais a complexidade e a sutileza do mundo amazônico. Na orelha do livro, lê-se o seguinte comentário:

O fim do terceiro mundo: não mais "inferno verde" ou "paraíso perdido", a Amazônia aparece neste romance desnudada em sua integração com a ordem econômica mundial. O calor de Manaus já não estonteia os alienígenas que, climatizados, levaram Manaus a conhecer também orgasmos de mais-valia e a síncope da boa vontade da media internacional. O fim do terceiro mundo está lá e acontece agora. (SOUZA, 1990)

Seguindo nesse mesmo diapasão há outros nomes que poderíamos seguir enumerando, mas a lista ficaria imensa e desnecessária. Para o nosso propósito bastam esses exemplos, indicando que a literatura dessa região teve e tem a incumbência de assumir para si o papel de crítica social e sempre incluiu em suas linhas as influências, pressões e constrangimentos ecológicos e ambientais que, partindo de fora do país, podem frear ou inviabilizar o desenvolvimento, transformando a Amazônia em um 
santuário ecológico para desfrute da vida selvagem, para vender para o ecoturismo exótico e de aventura.

No entanto, a literatura produzida na região se apresenta diversificada com a presença de variados gêneros e vertentes que estão em constantes transformações e, portanto, apontando sempre para um devir. Três dessas vertentes são claramente delineadas em dois autores paraenses e um amazonense: a vertente representada por Salomão Laredo (que mistura o tradicional e o contemporâneo em suas narrativas); a segunda vertente se desenha na literatura de Edyr Augusto (com temas atuais de cenas da vida urbana); a terceira linha está representada por Milton Hatoum (que apresenta temas mais tradicionais com cenas da vida cabocla mesclada à história da região). Há uma vertente intermediária que se alimenta de todos esses segmentos, representada por Haroldo Maranhão, navegando pela modernidade sem deixar de ser pós-moderno. Entretanto, não significa que a natureza não tenha mantido a sua força sobre o homem, como demonstra a literatura escrita até por volta dos anos 80 do século passado (vide Dalcídio Jurandir e Benedito Monteiro); sua presença é tão marcante sobre o homem que Viana Moog escreveu que na "Amazônia não há uma grande civilização não por culpa do homem, mas por culpa do meio" (MOOG apud BATISTA, 2007, p.131)

Apesar do esforço e do controle de alguns setores sociais e governamentais que tentam manter o território amazônico livre de influências de elementos estrangeiros, e mesmo nacionais, é um território invadido por signos culturais de toda ordem e de todo lugar em área considerável que não pode ser desprezada em termos de extensão. Veja como exemplo as áreas urbanas que já estão tomadas por signos de "fora", o interior da floresta, que apresenta problemas crônicos quanto à invasão estrangeira desde pelo menos o tempo áureo da extração da borracha, e as áreas de fronteiras, que estão se tornando um verdadeiro caldeirão cultural, com a convivência de elementos diversificados. 
A presença de elementos outros e a sua consequente integração no cotidiano dos cidadãos provocam transformações que, embora não exterminem a tradição cultural, que permanece relativamente preservada, ocasionarão "diferenças" na produção artística e cultural e na forma de narrar a Amazônia. Um estudo dessas construções narrativas, históricas, artísticas e críticas indica uma forma de entender nossa particularidade (aquilo que permanece), bem como aquilo que partilhamos com o mundo globalizado, mas já integrado ao nosso meio. As três vertentes literárias aqui apontadas são indicadoras da diversidade cultural e identitária que caracteriza a região. É perceptível como uma nova literatura que surge de um trauma histórico é responsável pelas palavras mais agudas que já se voltaram contra o lógos europeu sobretudo na literatura que tematiza de modo mais incisivo a história observada tanto na obra do amazonense Milton Hatoum quanto em alguns romances do paraense Haroldo Maranhão.

Um outro aspecto dessa questão indica que a consolidação da região no mundo capitalista internacional tenha se dado pela porta dos fundos da globalização (a cobiça estrangeira, as especulações em torno de seus bens materiais, os conflitos agrários, as demarcações de terra, a luta internacional pela preservação do meio-ambiente, etc.) e a torna inapta a qualquer pensamento otimista em torno de sua história. Tal processo, no entanto, pode ser considerado como ponto positivo para a compreensão de seu papel no mundo contemporâneo e seu futuro como região globalizada: não mais a considerando como o Paraíso Terrestre, visão vinculada a um discurso tradicional que vem desde os primeiros desbravadores europeus, amplamente conhecida na literatura do maravilhoso, mas sim como fronteira aberta, território expandido, tornando a Amazônia um lugar privilegiado de encontros e diferenças e de possibilidades de produção do novo, de sociabilidades, conhecimentos, culturas.

Esse processo de globalização assinala a questão fronteiriça para além de questões geográficas, envolvendo uma 
série de elementos culturais que nos remetem ao sentido de identidade vinculado ao espaço, tal como a formação e transformação de paisagens, entre outros, sinalizando a literatura um convite a uma aproximação a novos tipos nacionais, a invenção de heróis, e a uma nova forma de narrar a região, tendo como guia a inquietação por apresentar a forma como os discursos foram entendidos no continente latino-americano. Ela também se apresenta como desveladora do papel que tais discursos desempenharam e ainda desempenham na formação da identidade amazônica. Como podemos observar nas leituras realizadas da literatura contemporânea, a inquietação pelo processo chamado por alguns estudiosos de "desterritorialização" tornou-se praticamente um lugar-comum entre os autores que denunciam cada vez mais os rumos a serem tomados frente ao mundo globalizado.

Como território e paisagem privilegiada, a Amazônia é um espaço geográfico e político de grande importância para o Brasil e para o mundo por ser um lugar vital para o homem que dela depende para a sua sobrevivência (o manancial biológico e mineral da região é inquestionável e amplamente divulgado). Por esse motivo, a região se tornou cobiçada não só pelas grandes potências mundiais, que buscam explorá-la e dela extrair a riqueza que lhes interessa, mas também por instituições de pesquisa que buscam cada vez mais compreendê-la com o intuito de somar conhecimentos para o homem. A exploração da região envolve questões políticas, econômicas, culturais e interesses diversos que vão além de suas fronteiras que denunciam o olhar do outro sobre a Amazônia.

Questionar esse olhar é buscar a compreensão sobre como a Amazônia está sendo vista por terceiros, abordando aspectos mais específicos da relação centro/periferia e colocarmos em questão nossa origem nós mesmos. É também buscar a compreensão de como se constitui a periferia chamada Amazônia em relação ao mundo e ao continente americano e equacionar 
como uma nação orgulhosa de si mesma, de sua ancestralidade romana e de seu legado cristão parte em busca de novos espaços a fim de conquistá-los e de como essa busca prolonga a exploração sob novos parâmetros e sob uma nova denominação. A análise desse momento está exposta na literatura contemporânea da região, como, por exemplo, nos romances $O$ tetraneto del-rei e $O s$ anões, do escritor Haroldo Maranhão, e em alguns poemas de Thiago de Melo.

A Amazônia exótica é representada, por um conjunto de discursos dispersos em diversificadas narrativas, críticas, documentos históricos, cinema e televisão, cujos traços caraterísticos tem sua origem em um tempo remoto, renovado a cada período. São imagens do discurso da alteridade que reinventam o mundo desconhecido a fim de que possa ser reconhecido ou criar a ilusão de sê-lo, por meio de uma visão unilateral estabelecendo parâmetros de orientação e conduta em relação ao outro. Essa construção, no entanto, vai de encontro à literatura da região.

As representações sobre o outro no Ocidente têm um longo percurso. A Amazônia exótica tem uma história consolidada por uma tradição discursiva que começou com Frei Gaspar de Carvajal (1542) e Cristoal de Acuña (1641), que apresentava a região aos europeus por meio de informações colhidas em viagens. Tal narrativa continua a edificá-la através dos mais variados meios pelos quais a Amazônia é inventada e reinventada constantemente, tornando-se um mito sempre renovado a cada período histórico, de acordo com os interesses da época. Sob esse ponto de vista, sua representação é orientada por uma ideologia política determinando as regras do jogo no tabuleiro político mundial e criam as imagens seguindo o vento do capitalismo ocidental. Por isso, questionar os valores que regem os atos políticos e pedagógicos relacionados à região é questionar o saber ocidental que funciona como diretriz de domínio. O princípio norteador que rege o pensamento colonizador é a busca do conhecimento do outro, pois conhecer é dominar. Eis aí a premissa para quem deseja 
dominar (colonizar) aquilo que ainda é estranho: nomear, domar. Dar nome foi uma das tarefas em que se empenharam os europeus a fim de caracterizar o outro e a partir daí torná-lo conhecido, por meio de estereótipos. A região foi nomeada por seus exploradores, que lhe chamaram Amazônia. O termo Amazônia vem do grego amazoi, sem peito, e foi usado pela primeira vez como ideia de espaço pelo Barão Santa Anna Néri no livro Opaís das Amazonas, publicado em 1899, e se refere à lenda das amazonas. Ao chegar à região, os europeus imaginaram ter encontrado as guerreiras ao se depararem com índias que portavam o arco e a flecha (em contraste com as mulheres de seu continente, dedicadas às tarefas domésticas).

Desde a chegada do homem europeu, a Amazônia vem sofrendo investidas pesadas que não cessaram até hoje com as novas configurações de exploração e domínio sobre as riquezas que marcam o período da pós-colonização. Se antes eram os europeus que invadiam a região interessados em seus produtos exóticos que se integravam no complexo sistema de troca, hoje essa invasão é feita por países de todos os continentes, mas principalmente pelas grandes potências mundiais que investem no intuito de integrar cada vez mais e de forma mais cruel a Amazônia no cenário econômico mundial.

O livro Orientalismo, de Edward Said, foi a obra que questionou a construção de imagens, estereótipos e dogmas relativos a realidades culturais outras; neste caso, o Oriente. $\mathrm{O}$ autor defendeu que a visão do Oriente tem sido uma construção intelectual, literária e política do Ocidente como meio de ganhar autoridade e poder sobre o primeiro. Nesse sentido, podemos aproximar, guardando as inevitáveis diferenças, o termo amazonismo à noção de "orientalismo", a fim de compreender a origem e as formas de abordagem que norteiam programas políticos, econômicos e culturais sobre a região, bem como as justificativas que sustentam as investidas do mundo capitalista, empenhado cada vez mais, e muitas vezes de forma sutil, em inserila no contexto da globalização. Numa concepção acadêmica, o 
termo amazonismo se aproxima da noção empreendida por Edward Said como um conjunto de ideias produzidas pelo imaginário ocidental sobre a região amazônica. As representações são diversificadas e erigidas por construções que tentam dar conta de uma totalidade, reconstruindo sempre a imagem exótica e estereotipada, observada desde a perspectiva dicionarizada do termo Amazônia, como o verificado no Novo dicionário aurélio da língua portuguesa que assim define o amazonismo:

1. Amazonismo sm (amazona +ismo), nome dado à lenda ou existência real das amazonas, e que abrange as opiniões pró e contra. 2. Sacrifício dos machos, depois da união sexual. 3. Adoção, por mulheres, de hábitos e ocupações considerados masculinos. 4. amazonismo (Amazonas, $n p+i s m o$ ) Bairrismo pelo Amazonas ou exagerado sentimento ao que é da região amazônica. (FERREIRA, 1986, p. 101)

Percebe-se que o vocábulo é utilizado em muitos e diferentes sentidos, que levam o termo a generalizações e equívocos, por vezes, exagerados. Com isso, emprega-se a palavra em situações tão diversas quanto contraditórias, como, por exemplo, desde nas declarações contrárias à política da ex-Ministra do Meio Ambiente, Marina Silva, em relação à Amazônia: "abaixo o amazonismo do MMA..." até nas descrições de cenas de lesbianismo ou comportamentos homossexuais femininos.

Nos dias de hoje, não mais predomina a imagem de região exótica como "inferno verde", "pulmão do mundo", nem a do medo causado pelas grandes distâncias, os rios e as florestas infindáveis, o caboclo, a fauna e a flora, o selvagem, que alimentavam o imaginário ocidental. Hoje a preferência é por outro tipo de imagem que atenda aos interesses das grandes potencias mundiais, divulgadas com interesses econômicos como forma de atrair investimentos do capital estrangeiro na região. Usadas com fins também turísticos, elas circulam no mundo funcionando como mecanismo de reforço do discurso tradicional, estabelecido desde 
os primeiros navegantes, que produziam informações com intuito de explorar a Amazônia.

Outra vertente de estereótipo utilizado com fins econômicos é a imagem da fartura em função da imensidão que a Amazônia representa. As matérias-primas não terminam jamais e estão sempre à espera de capital, servindo como fonte de renda para os governos dos estados que lançam mão desse recurso expressivo para atrair investimentos estrangeiros e mão-de-obra de outros estados. Seguindo essa linha, a Amazônia é colocada por esse tipo de propaganda como o lugar sempre pronto a receber investidas, pois seu manancial material e bilógico nunca se esgota. Dessa forma, haverá sempre espaço em abundância e produto in natura o suficiente para todo e qualquer tipo de investimento que deseje explorar a região e contribuir para o seu engrandecimento. $\mathrm{O}$ estereótipo aqui veiculado é o da inesgotabilidade da região, já que apresenta um manancial comprovadamente sem fim.

Ora, veja-se bem que os estereótipos são utilizados como meio de atrair capital estrangeiro para a região com o intuito de desenvolvê-la, através da veiculação de discursos similares àqueles verificados em obras de autores que sobrevalorizam a cor local. É fácil observar que o estereótipo tem como objetivo atender a uma necessidade do gosto pelo exótico. A imagem do índio e do pomposo hotel cinco estrelas em plena floresta dá a ilusão de que a natureza fora domesticada.

Desse modo, de acordo com o exposto, o amazonismo se constitui em imagens positivas e negativas da região, mas sempre como reforço de uma tradição e de uma única intenção, cujo interesse é econômico. Ao contrário do que se pensa, as imagens da região não são contraditórias, desde aquelas produzidas pelos conquistadores até as mais atuais se restabelece o mito das Amazonas, Eldorado, Inferno Verde, etc. a fim de legitimarem os interesses políticos e ideológicos da Europa.

Em virtude de interesses ecológicos generalizados, contemporaneamente pensa-se na região como o território que 
deve ser mesmo protegido das especulações produzidas pela ganância econômica - esse é o pensamento predominante entre os militantes de ONGs, associações científicas e grupos de militantes ecológicos. O mundo olha para a Amazônia segundo o interesse individualizado das nações e em conformidade com as demandas de um mercado global, estabelecendo, nesse ponto, um impasse: como proteger a região das garras de um mundo que necessita de espaços para se expandir e, ao mesmo tempo, proteger um importante manancial de riqueza ecológica que também interessa a todos? Explorar e preservar, ou explorar sem deplorar, explorar racionalmente? O que significa explorar sem exaurir as riquezas de uma região da qual todos dependem para sua sobrevivência?

O problema se torna muito complexo, abrindo-se um impasse, pois para o capital internacional o termo Amazônia é um vocábulo que faz parte definitivamente dos planos de ação de governos e blocos econômicos no contexto do capitalismo internacional, o que a torna talvez a região mais economicamente central, isto é, do ponto de vista do capital internacional, o que a torna inevitavelmente a região mais globalizada do mundo. A inserção da região no circuito econômico do mundo leva à crença de que não é mais possível isolá-la, já que para ela convergem elementos externos, diferenciados e divergentes, vindos dos quatro cantos do planeta. Essa descoberta encanta, inquieta e atemoriza, ao mesmo tempo. A integração da região no mundo, antes supostamente protegida pela floresta, rios e distâncias, e fechada em sua cultura, provoca uma ruptura drástica nos modos de ser, sentir, agir, pensar e fabular, afetando a identidade desse imenso território, produzindo um evento histórico de grandes proporções, que abala não só as convicções, mas também as visões do mundo estampadas na arte e na literatura da região. Esse abalo tem se refletido na crítica literária local, que, no intuito de recuperar o elo com o passado, especula por meio de expressões as peculiaridades de uma região em fase de ruína. 
Sem se dar conta desse processo, a crítica regional aponta para uma tentativa de recuperação de unidade cultural do lugar que a própria literatura produzida na região e/ou nela ambientada demonstra não existir. A posição dessa crítica, como todo ato crítico, defende uma ideologia e uma política de interesses particularizados de preservação de manifestações literárias de vertente única, classificando a literatura local como "Literatura de Expressão Amazônica" ou "Literatura Brasileira de Expressão Amazônica", que aponta para uma particularidade regional, uma "cor local", um lugar exótico, impenetrável e diferenciado do resto do mundo. São tentativas de reunir em um só lugar o que é, por natureza, diverso. Para se perceber a diversidade da região, basta olhar para os autores, períodos e nacionalidades tão diferentes quanto antagônicos que versam sobre a Amazônia, constatando que a região é tão rica quanto contraditória, ao longo de sua história. A literatura dos vários países que a compõem, cada qual com sua particularidade: o período histórico-literário ao qual pertencem, os temas, a problemática, o homem e a cultura mudam de acordo com o espaço ocupado e com o tempo no qual estão inseridos.

Portanto, estudar as representações da Amazônia no discurso literário é ocupar-se, por um lado, de imagens, ideias e pontos de vista que se formaram e continuam se formando, no Brasil e no exterior, sobre a região amazônica e sua cultura, a fim de constituir um arcabouço representativo dos estereótipos. Por outro lado, trata-se de descobrir o sentido das construções sobre a Amazônia, os interesses que as motivam e a ideologia constitutiva do discurso sobre o outro que se dá em lugares distantes nos quais se pensam e nomeiam o espaço amazônico.

Tendo em vista essas reflexões, podemos dizer que a literatura da/sobre a Amazônia está voltada para temas e assuntos que problematizam a região no contexto mais amplo da história e da cultura latino-americana, sem necessariamente descrever o mundo verde da floresta, conforme tentaremos demonstrar nas páginas seguintes. 
Ángel Rama, ao enfocar as regiões culturais e literárias da América Latina, aponta para a diversidade do continente, verificada pelos analistas de várias disciplinas. Esses estudos demonstram que alguns países hispanoamericanos, regidos pela variedade, foram capazes de constituir nações graças a fatores integradores. Predomina no continente a diversidade cultural, desenhando no mapa um mosaico, com maior ou menor intensidade conforme a história de cada país. Neste caso, "[a] divisão em regiões, dentro de qualquer país, tem uma tendência multiplicadora que em caso limite produz uma desintegração da unidade nacional" (RAMA, 1989, p. 58).

Rama aponta o perfil de Minas Gerais como exemplo da divisão em sub-regiões com tendência desintegradora delineada na obra de Guimarães Rosa, cujo recorte estabelece fronteiras em relação ao resto do país. Do mesmo modo, o crítico cita a obra de Márcio Souza, Galvez, o imperador do Acre, como representativa de uma região que não está no mapa oficial do Brasil. Para o crítico, o Brasil de Rosa, Márcio Souza e outros escritores mencionados por ele, é mais verdadeiro que o oficial, determinado pelas velhas divisões administrativas da colônia. As narrativas desses autores contradizem as normas nacionais predominantes que tentam impor língua, educação, desenvolvimento econômico, sistema social com a intenção de constituir influência considerável na conformação nacional.

Para melhor ilustrar a complexidade cultural do continente, pode-se recorrer aos estudos de divisões em microrregióes, bem aplicados a países como o Brasil, "cujas dimensões, variedade de condições ecológicas, componentes étnicos, fatores históricos, produções, etc., tem propiciado o desenvolvimento interno de culturas internas" (RAMA, 1989, p. 60). Desse modo, um dos estudos mencionados por este autor, o que fora desenvolvido por Wagley, determina seis grandes regiões no Brasil que representam fendas culturais dentro da unidade. Dentro dessa classificação, duas estão relacionadas à região 
amazônica: Vale Amazonas e Fronteira Oeste, que dá a ideia da variedade cultural interna da região. A complexidade do continente, pensado por Wagley, bem pode ser aplicada à Amazônia:

Acho necessário pensar na América Latina em termos de regiões, cada uma das quais tem um tipo diferente de tipo físico, população de diferente composição étnica e distinta variedade de cultura latino-americana. (RAMA, 1989, p. 60)

Os elementos presentes na sociedade transculturada compõem um quadro que privilegia a expansão horizontal de subculturas reconhecendo hábitos e comportamentos geradores de produtos que respondem ao consenso geral dos homens dentro dos limites regionais. Assim, nas esferas regionais, os homens são portadores de usos culinários, sistema linguístico, crenças e valores que impregnam a todos os membros da comunidade, diferenciando-os dos de outras regiões.

No mundo globalizado ocorre o processo de transformação da identidade, que deixou de ser fixa, ou essencial, para tornar-se "uma celebração móvel: formada e transformada continuamente em relação às formas pelas quais somos representados ou interpelados nos sistemas culturais que nos rodeiam" (HALL, 2001, p. 13). A América Latina, no entanto, resiste à pulsão modernizadora por meio da recuperação de elementos culturais locais, que permanecem e fazem frente às tendências homogeneizadoras das culturas internas. Somos levados a pensar, inicialmente que a identidade cultural está sendo reforçada pela resistência à globalização. Entretanto, não se pode ignorar que as identidades locais são largamente penetradas por influências sociais de longas distâncias. Ou seja, ao lado da tendência homogeneizadora, há, também, a valorização da diferença, um despertar para o local e o olhar para o outro. Desse modo, ao invés de se pensar o global como esfacelamento, destruição ou mesmo substituição do local, seria mais correto pensar numa nova 
articulação entre o local e o global, resultando em novas dinâmicas sociais que misturam retalhos cotidianos.

Os fragmentos ou as várias zonas que formam a cultura interna, mescla de tradição e modernidade, estão estampadas de forma magistral no romance Dois irmãos de Milton Hatoum na convivência de elementos da culinária amazônica e libanesa, de odores e sabores que se misturam, constituindo um corpo híbrido submetido a sucessivas e variadas transformações e acréscimos, como demonstrado no fragmento seguinte:

No restaurante manauara ele preparava temperos fortes com pimenta-de-caiena e a murupi, misturava-as com tucupi e jambu e regava o peixe com esse molho. Havia outros condimentos, hortelã e zatar, talvez. (HATOUM, 2000, p. 63)

Nesse fragmento, verifica-se que o elemento externo passou a ocupar um outro lugar, nem lá, nem cá, sem hierarquia, já que o deslocamento operado no significado foi duplo. Esse terceiro elemento, ao ser manuseado pela comunidade, adquire um caráter local e, ao mesmo tempo, transculturado, já que passa a assumir um lugar dentro da comunidade.

Outro aspecto significativo de entrelaçamento cultural estampado no romance de Hatoum são as histórias que se cruzam, as línguas misturadas, ativando a memória, intervalos e silêncios:

Falavam português misturado com árabe, francês e espanhol, e dessa algaravia surgiam histórias que se cruzavam, vidas em trânsito, um vaivém de vozes que contavam um pouco de tudo... (HATOUM, 2000, p.48)

É nesse território rompido, transculturado, permeado por múltiplas vozes e línguas, que se desenha o quadro cultural de uma cidade situada na parte mais central da Amazônia, onde há "uma mistura de gente, de línguas, de origens, trajes e aparências" (HATOUM, 2000, p. 53). Essas vidas produzem uma conjuntura constituída por diversas forças e uma nova dinâmica cultural na 
região, oferecendo ao leitor do romance renovadas cenas amazônicas.

Esse novo quadro, nascido da interseção de vários elementos culturais, é atravessado por signos, símbolos e manifestações sociais que impregnam e contaminam a unidade nacional. Em sua reflexão a respeito da nação como narração, Homi Bhabha aponta para a metáfora progressista da coesão social como discurso que tenta expressar as experiências sociais como totalidade, em detrimento de diferenças de gênero, raça ou classe (BHABHA, 1998, p. 202). Para se pensar a nação, é necessário olhar para as problemáticas fronteiras, as fissuras do presente, que estão encenadas nas temporalidades ambivalentes do espaço-nação.

Citando um estudo de Bakhtin sobre Viagem a Itália, de Goethe, Bhabha aponta para a força da narração de revelar, nos detalhes da vida cotidiana, aspectos que emergem como metáforas da vida nacional:

É a visão do microscópico, do elementar, talvez do aleatório passar da vida cotidiana na Itália, que revela a história profunda de sua localidade (Lokalität), a espacialização do tempo histórico. (BHABHA, 1998, p. 203)

Nesse sentido, aspectos diferentes de uma cultura recalcada são destacados como expressão insurgente de um projeto discursivo transgressor, enunciando um modo de vida ampliada, perturbadora da metáfora da identidade nacional e inscrevendo-se no tempo disjuntivo da modernidade da nação:

Os fragmentos, retalhos e restos da vida cotidiana devem ser repetidamente transformados nos signos de uma cultura nacional coerente (...). Na produção da nação como narração ocorre uma cisão entre temporalidade continuísta, cumulativa, do pedagógico e a estratégia repetitiva, recorrente, do performativo. (BHABHA, 1998, p. 207) 
Sob esse ponto de vista, teorizado por Bhabha, poderemos averiguar, nas páginas seguintes, que Milton Hatoum realiza uma importante reflexão sobre o espaço e o tempo nacionais através do enfoque do espaço interrompido, do tempo disjuntivo, dos fragmentos e retalhos do cotidiano de uma cidade.

Representante de uma nova vertente literária, o escritor manauara - assim como o paraense Haroldo Maranhão, tão diversos quanto ao estilo, à temática, ao uso da técnica narrativa $\mathrm{e}$ à construção do texto - não é, no entanto, menos enraizado em sua região quanto aqueles que se preocupavam com a descrição direta da cor local. Cada um, a seu modo, Milton Hatoum e Haroldo Maranhão, busca relatar o mundo amazônico, sua história, seus costumes, sua formação social e o intercâmbio que se dá com outros povos do mundo, o rompimento de fronteiras e o entrelaçamento com a história e a cultura do outro. Sem enfocar a região como um local isolado e fechado em sua essência regionalística, esses dois autores a descrevem como uma zona que realiza uma troca fecunda com todos os setores da vida moderna, dinamizando essa parte do país.

Milton Hatoum, considerado por muitos como um dos mais importantes escritores de sua geração, tematiza em seus livros a presença da cultura libanesa em Manaus, tendo como cenário as ruínas da cidade. Maranhão, por sua vez, escreveu, entre outros, um texto instigante, híbrido de ficção, história, documento e biografia para falar de um personagem responsável por um dos mais inflamados episódios da História do Brasil, ainda pouco conhecido dos brasileiros, relacionado à Independência e à libertação dos povos da Amazônia.

O romance de Milton Hatoum gira em torno dos conflitos e das diferenças entre os irmãos gêmeos Yakub e Omar, relatados desde o início do livro e vão se acirrando até o final da narrativa quando Yakub investe contra sua família, que não resiste ao seu golpe e se esfacela: Yakub vende a casa para um comerciante que a transforma na Casa Rocheram, destruindo de vez a memória 
familiar. Das ruínas da casa, resta apenas um pequeno quarto no quintal, onde mora Nael, filho de Domingas com um dos gêmeos. Embora o tema central do romance dramatize o destino das personagens, enredadas em impasses e contradições, trataremos da ocupação do espaço da família de imigrantes na Amazônia, vista sob a perspectiva da cidade sem raiz, do lugar de dispersão, segundo Luiz Costa Lima (LIMA, 2000, p. 18-19). O espaço transitório é o ponto sobre o qual investe a narrativa, confrontando uma visão corrente de lugar exótico, intocável, livre de interferências e percebido como a "fronteira extrema do imaginário brasileiro" (MIRANDA, 2000, p.1-2). Sob essa perspectiva, o lugar se aproximaria da visão nacionalista de pátria, entendido como lugar antigo que identifica e fortalece os sentimentos de pertencimento e de história compartilhada e relaciona a algo que lhe é interior e anterior. A nação oficial seria o lugar de conservação de patrimônios históricos e acumulação de bens comuns, definido pelo governo, museu, revoluções, enfim, tudo o que é institucionalizado.

Dois irmãos enfraquece estratégias unificadoras de nação, o "muitos como um", ao apontar um país dividido entre a luz e a escuridão, metaforizado na inauguração de Brasília, cidade construída racionalmente, e a euforia que isso causa aos brasileiros, por oposição a uma Manaus que vive o racionamento de energia elétrica. As diferenças e a distância entre o Norte e o Sul ganham destaque no confronto entre a riqueza e o progresso de São Paulo e a decadência de Manaus.

Do mesmo modo, o romance nos leva a refletir sobre o que é ser brasileiro no Norte do Brasil, numa cidade cercada por florestas e rios, habitada por imigrantes, caboclos e índios. Esses elementos, certamente, reproduzem na cidade marcas étnicas que estão presentes na alimentação, habitação, medicamentos, vocabulário e tecem redes de solidariedade, amizade e conflito, misturando signos locais e outros vindos do exterior, trazidos por imigrantes. 
A diversidade e a mistura de elementos em Dois irmãos, no entanto, estão relacionadas não só com a urdidura da narrativa, mas também com a noção de multiculturalismo, e com a cisão entre o discurso pedagógico e estratégias performativas. O autor escreve a nação através do cotidiano de uma cidade e da vida familiar, de um elemento urbano que, juntamente com outros, constrói uma rede social. O discurso pedagógico de unidade cultural é denunciado na desobliteração do tempo presente que desestabiliza imagens homogeneizantes e introduz a heterogeneidade da população.

A cidade de Hatoum constitui uma cidade flutuante, compreendida enquanto lugar que se esvai e se afasta de sua raiz, contrariando a noção corrente de pertencimento e identidade, fixada em uma localidade determinada e nacionalizada, para se aproximar da ideia de território, ou seja, de um espaço flou, envolvido por uma atmosfera volúvel que problematiza as relações de identidade.

Nesse espaço de transição, todos parecem mal-ajustados no lugar que parece não ser o seu. Incomodados, aguardam o momento de partir, à exceção de Zana, que está sempre no controle de tudo. Na casa de Zana, agregados e descendentes estão condenados a viver uma vida que se dissipa e se desestabiliza a cada encontro, como se estivessem num cenário estranho. As personagens, uma a uma, vão se afastando do espaço compartilhado da casa de Halim e saem em busca de outros lugares, na tentativa de resolver seus conflitos internos.

A narrativa põe em jogo a questão da divisão do espaço que é marcado pela divisão da sociedade em classes. Tanto na cidade, quanto na casa de Halim, os espaços são loteados de acordo com a função e o poder do ocupante. A começar pela localização, a casa de Halim e Zana está situada entre a igreja e o porto, na Rua dos Barés, onde todos passam, num movimento intenso, anunciando um lugar estratégico, centralizador, que domina todo o resto da cidade e em torno do qual tudo gira. Às 
margens desse poder, situa-se a periferia e o bairro flutuante, lugar de despossuídos e miseráveis, onde vivem pessoas como Dalia, a Mulher Prateada, cujo poder de sedução e brilho é logo ofuscado por Zana.

Da margem também veio Domingas, a índia domesticada, para trabalhar na casa de Zana. Embora tenha deixado o humilde lugar onde nascera, sua situação social não muda, pois ocupa um espaço limitado entre muros. Sua situação ainda se agrava quando nasce Nael, pois, além de estar fora de lugar, agora se encontra sem voz por não poder contar ao filho sua própria origem.

O que aí se instala é um tipo de poder centralizado que impede de dizer e interfere diretamente no destino e na vida cotidiana das pessoas, estabelecendo as relações sociais onde cada um desempenha seu papel e se sente estrangeiro no espaço do outro. Nesse sentido, o bairro flutuante é o lugar fixo de seres anônimos, perdidos no emaranhado confuso de suas casas e ruas, palafitas sobre as quais se estabilizam, deslocados ou fugitivos do mundo, moradores de lugar nenhum, nem da floresta, nem da cidade, nem ribeirinhos, nem citadinos. Localizados à margem da cidade, os moradores tentam se adaptar ao asfalto, sem sucesso. Se levarmos em consideração a noção de lugar como algo específico, conhecido, familiar, delimitado, veremos que a geometria do poder, estabelecida pelo processo de globalização, produz sistemas de organização social que geram identidades desvinculadas, desalojadas de lugares, tempos e tradições. Essa articulação traz uma flutuação livre de identidades (HALL, 2001, p. 75).

É a lei da divisão social que cria um movimento de separação e função espacial e estabelece fronteiras bem demarcadas socialmente, o que os sociólogos chamam de segregação. É como se cada espaço fosse definido por cercas imaginárias, determinando o lugar de cada um. Isso ocorre, por exemplo, na relação entre Zana e Domingas. A empregada pode 
rezar e orar ao lado de Zana, mas mora no quarto dos fundos, separada por grossas paredes que determinam as diferenças. Do mesmo modo, Nael senta-se à mesa com a família de Halim, porém, somente quando é permitido por Omar, o que marca o espaço do trabalho e da moradia e torna visível o tratamento por parte dos patróes. Para os membros da classe dominante, a proximidade do território popular representa um risco permanente de contaminação. Por isso, Nael só entra na casa de Estelita pela cozinha e, mesmo assim, precisa tirar as sandálias. Do mesmo modo que a Mulher Prateada é expulsa da casa de Zana, bem como outras pretendentes ao coração de Omar.

Por outro lado, no território popular a sobreposição de funções e o uso coletivo do espaço é questão de sobrevivência. Por isso, Domingas e Nael dividem o mesmo quarto por um bom tempo e no final do romance, esse mesmo quarto, ao se desligar da casa que pertencera a Halim e Zana, passa a integrar o cortiço, lugar coletivo e de ninguém, onde Nael, na verdade, sempre esteve.

O bairro flutuante, por sua vez, reflete o desenho social da margem que não obedece a qualquer traçado pré-estabelecido. No movimento de ocupação desse território, de linha irregular e espontânea, reflexo da vida tortuosa, sinuosa e descontínua, seus habitantes constroem um bairro labiríntico, assim como é labiríntico o mapa de rios da Amazônia. Situado na fronteira entre duas margens, a terra firme e o rio, esse espaço denota a vida minada e fragmentada dos seus moradores. Era nesse lugar híbrido que Halim papeava com um compadre, sentado à mesa de um boteco. Para Halim o labiríntico bairro flutuante era lugar de refúgio e de alívio para suas dores, próximo de um locus amoenus.

De uma maneira geral, a cidade de Dois irmãos parece um outro lugar, que não se confunde com uma megalópole, nem com uma cidade clássica, nem com um vilarejo. É uma cidade órfã onde mais se difunde a divergência de seus elementos do que propriamente de seu encontro: Nael desconhece sua origem; Yakub é rejeitado pela mãe; Rânia acaba solitária; Halim perde o 
amor de Zana; Domingas se sente fora de seu lugar. E a separação definitiva ocorre no final do romance: Yakub e Omar traçam caminhos opostos; Rânia muda de casa; Zana enlouquece; e Nael só encontra sossego quando se ergue o muro que separa a Casa Rocheram do seu quarto.

Assim, Manaus é o lugar da ruptura, atravessado por fissuras que a transformam no espaço simbólico da fragmentação. A cidade que perdeu o passado glorioso do período áureo do início do século XX e que agora definha sob a decadência moral e material, representada na imagem do outrora destemido desbravador da floresta, hoje um frágil coveiro, coxo e deslocado.

\section{Referências}

BATISTA, Djalma. O complexo da Amazônia: análise do processo de desenvolvimento. 2. ed. Manaus: Ed. Valer/Edua/Inpa, 2007.

BENCHIMOL, Samuel. Amazônia: formação social e cultural. 3. ed. Manaus: Editora Valer, 2009

BHABHA, H. K. O local da cultura. Trad. Myriam Ávila, Eliana Lourenço e Gláucia Renate. Belo Horizonte: Editora UFMG, 1998.

HALL, Stuart. A identidade cultural na pós-modernidade. Rio de Janeiro: DP\&A, 2001.

FERREIRA, Aurélio Buarque de Holanda. Novo dicionário aurélio da língua portuguesa. Rio de Janeiro: Nova Fronteira, 1986.

HATOUM, Milton. Dois irmãos. São Paulo: Companhia das Letras, 2000.

LIMA, Luiz Costa. A ilha flutuante. Folha de S. Paulo. São Paulo, 24 set. 2000. Mais, Brasil 501 d. C., p. 18-19.

MELLO, Thiago de. Amazonas, Pátria da Água e Notícia da visitação que fiz no verão de 1953 ao Rio Amazonas e seus Barrancos. 3. ed. Rio de Janeiro: Bertrand Brasil, 2005.

MIRANDA, Wander Melo. Dois destinos. Jornal do Brasil. Rio de Janeiro, 1 jul. 2000, Ideias - Livros, p. 1-2. 
RAMA, Ángel. Tranculturación narrativa en América Latina. Montevideo: Fundación Ángel Rama/Arca Editorial, 1989.

SAID, Edward. Orientalismo: o oriente como invenção do ocidente. Trad. Rosaura Eichenberg. São Paulo: Companhia das Letras, 2007.

SANTOS, Milton. A natureza do espaço. 4. ed. São Paulo: Ed. da Universidade de São Paulo, 2009.

SOUZA, Márcio. Ofim do terceiro mundo. São Paulo: Marco Zero, 1990. TRINDADE JÚNIOR, Saint-Claire. Pensando a noção de fronteira: um olhar a partir da ciência geográfica. In: NASCIMENTO, Durbens Martins. Amazônia e defesa: dos fortes às novas conflitualidades. Belém: NAEA/UFPA, 2010.

Recebido para publicação em 28 de fevereiro de 2012 Aprovado em 21 de março de 2012 